\title{
NOVA ESPÉCIE DE Enderleina JEWETT DO NORTE DO BRASIL (PLECOPTERA - PERLIDAE)
}

\section{Ana Celeste RIBEIRO-FERREIRA ${ }^{1}$}

RESUMO - Uma nova espécie de Enderleina Jewett, 1960, de Manaus-AM, é descrita, a segunda do Brasil e a primeira do Estado do Amazonas: Enderleina froehlichi sp.n.

Palavras chaves: Insecta, Plecoptera, Perlidae; Enderleina froehlichi; Amazonas

New Species of Enderleina Jewett from North of Brazil (Plecoptera - Perlidae).

ABSTRACT - A new species of Enderleina Jewett, 1960, from Manaus-AM, is described; it is the second Brazilian species and the first one for the State of Amazonas: Enderleina froehlichi sp. $\mathrm{n}$.

Key words: Insecta, Plecoptera, Perlidae; Enderleina froehlichi; Amazon.

\section{INTRODUÇÃO}

O gênero Enderleina, com a única espécie $E$. preclara, foi estabelecido por JEWETT (1960). STARK (1989) descreveu três espécies do sudeste da Venezuela: $E$. flinti, E. yano, E. bonita. Neste trabalho é descrita uma espécie nova, E. froehlichi.

Este é o segundo registro do gênero para o Brasil,sendo o primeiro para o Estado do Amazonas.

\section{MATERIAL E MÉTODOS}

O material estudado foi criado em laboratório: uma ninfa de penúltimo estádio foi coletada na Reserva Florestal Adolpho Ducke, na rodovia AM 010, $\mathrm{Km} 26$, Igarapé da Anta com temperatura de 25 graus Celsius, águas pretas (segundo a classificação de SIOLI $(1965,1967))$, coberto pela floresta de terra firme, com leito arenoso e folhiço, e com uma velocidade de sete segundos e dezesseis centésimos. Posteriormente trazida ao laboratório, foi colocada em um insetário contendo bandejas com água do igarapé (riacho) e telado com tecido de filó.

A duração deste estádio até a emergência ocorreu em sete dias. $\mathrm{O}$ adulto foi fixado em álcool $80 \%$, em seguida dissecada a genitália, clarificada em $\mathrm{KOH} 10 \%$, desenhada e preservada em glicerina.

Enderleina froehlich, sp. $\mathrm{n}$.

(Figs. 1-6)

Diagnose: corpo acastanhado, asas castanho-claras, pernas acastanhadas; armadura penial com a porção apical afunilada e dois pares de processos basais laminares terminando em dentes, paraprocto com um dente subapical.

Holótipo macho: largura da cabeça $1,9 \mathrm{~mm}$; comprimento da asa $7,5 \mathrm{~mm}$.

Cabeça castanho-clara com a porção anterior e próximo à base das antenas amarelo-claras, antenas longas amarelo-claras; pronoto castanhoclaro, mesonoto amarelo-claro, asas

Instituto Nacional de Pesquisas da Amazônia-INPA, Coordenação de Pesquisas em Entomologia, Caixa Postal 478 CEP 69011-970, Manaus,AM. 

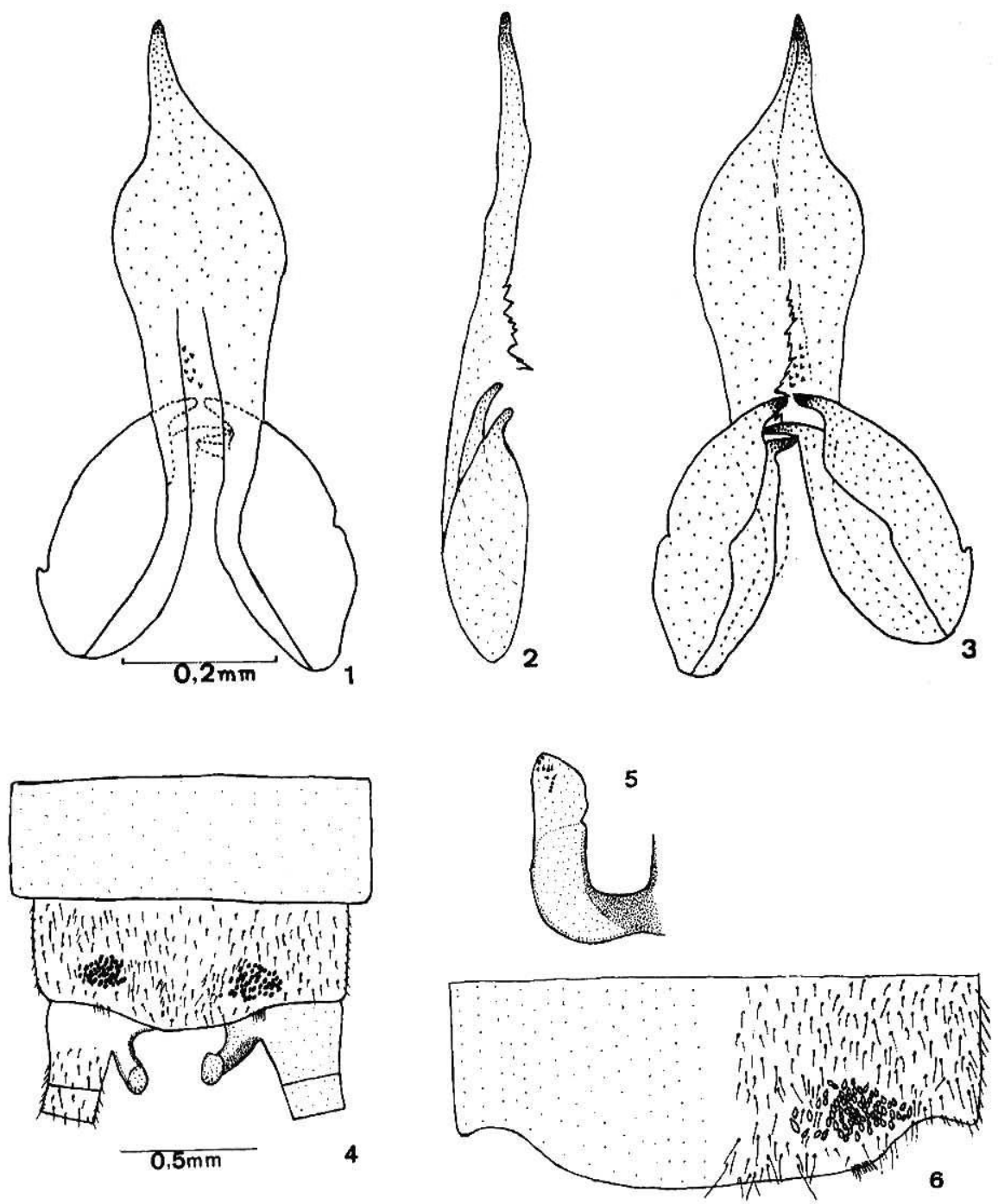

Figuras 1-6. Enderleina froehlich sp. n. Genitália do macho: 1 a 3- armadura penial, vista dorsal, lateral e ventral respectivamente; 4- paraprocto, lateral; 5- esternito 10 e paraproctos; 6tergito 10 . Todas as figuras na mesma escala. 
castanho-claras, trocânter, base das tíbias e tarsos castanhos, porção basal das tibias e tarsos com uma listra castanho-escura; abdome acastanhado, cercos longos amarelo-claros, armadura penial com a porção apical afunilada, parte mediana com uma fileira de dentes, e dois pares de processos basais delgados laminares (Figs. 1-3), paraproctos semisimétricos com um dente subapical (Figs. 4-5), tergito 10 com área circular dorsolateral, subapical vesiculosa (Fig 6).

\section{Fêmea desconhecida.}

Material examinado: Brasil, Amazonas, Manaus, Reserva Florestal Adolpho Ducke, AM 010, Km 26, 13/XI/ 1987, INPA, (A.C.R.Ferreira)

Etimologia. O nome da espécie é uma homenagem ao Dr. Cláudio Gilberto Froehlich, Plecopterista do Brasil.

\section{AGRADECIMENTOS}

Ao Dr. Victor Py-Daniel e Raquel Sampaio pela orientação e oportunidade de trabalho e aos técnicos Luís Aquino e João Ribeiro pelo acompanhamento e auxílio nas coletas.

\section{Bibliografia Citada}

JEWETT, S. G. (1960). Notes and descriptions concerning Brazilian stoneflies (Plecoptera). Arq. Mus. Nacional Rio de Janeiro, 50:167-184.

SIOLI, H. 1965. Bemerkung zur Typologie amazonischer Flüsse. Amazoniana, 1(1): 74-83

SIOLI, H. 1967. Studies in Amazonian waters. Atas do Simposio sobre a Biota Amazonica, 3: 9-50

STARK, B. P. (1989). The Genus Enderleina (Plecoptera: Perlidae). Aquatic Insects, 11(3):153-160. 